\title{
Tratamento térmico em Zamac visando diminuir defeitos de porosidade
}

\author{
Fernando Konarzewski Dienstmann ${ }^{1}$ \\ Luciane Taís Fuhr ${ }^{1}$ \\ Leonardo Felix Scheffel ${ }^{1}$ \\ Carlos Leonardo Pandolfo Carone \\ Fernando Dal Pont Morisso ${ }^{1}$ \\ Eduardo Luís Schneider ${ }^{1}$ \\ Sandra Raquel Kunst ${ }^{2}$ \\ Jane Zoppas Ferreira ${ }^{2}$ \\ Cláudia Trindade Oliveira ${ }^{1 *}$ (D)
}

\section{Resumo}

O Zamac tem sido utilizado na indústria galvânica, principalmente, devido ao seu baixo ponto de fusão, o que permite a obtenção de peças com riqueza de detalhes, tais como peças do setor moveleiro, moda e metais sanitários. No entanto, os processos de sua obtenção, por injeção sob pressão e injeção centrífuga, geram porosidade e, consequentemente, aumento de sucata. Por outro lado, estudos mostraram que fusão por gravidade não apresenta tais problemas. Nesse sentido, o objetivo deste artigo foi tratar termicamente peças de Zamac injetadas sob pressão, com a finalidade de obter comportamento semelhante às peças fundidas por gravidade. Para tanto, peças injetadas sob pressão foram tratadas termicamente, abaixo da temperatura de fusão. A caracterização morfológica dessas amostras foi obtida por MEV. Observou-se que o tratamento térmico acima da temperatura eutetoide apresentou melhor resultado com respeito à porosidade observada.

Palavras-chave: Zamac; Porosidade; Tratamento térmico.

\section{Heat treatment in Zamac to reduce porosity defects}

\begin{abstract}
The Zamac has been used in the galvanic industry mainly due its low fusing point properties, which allows obtaining very detailed parts, like parts for furniture industry, fashion and health metals. However, its production processes, like pressure injection and centrifugal injection, generate an increase in porosity as well as waste. On the other hand, studies show that die casting leaked Zamac doesn't show the same problems. In this sense, the goal for this work is to perform heat treatment in Zamac parts produced by pressure injection in order to obtain similar properties as the ones produced by die casting leakage. For this, the parts injected under pressure were thermally treated under their fusion temperature. It was observed that thermic treatment over the eutectoid temperature showed the best result, regarding the observed porosity.
\end{abstract}

Keywords: Zamac; Porosity; Heat treatment.

\section{Introdução}

O Zamac é uma liga metálica não-ferrosa composta basicamente por quatro elementos. Zinco (Zn), Alumínio (Al), Magnésio $(\mathrm{Mg})$ e Cobre $(\mathrm{Cu})[1,2]$. Com baixo custo e facilidade de ser injetado sob pressão, ele proporciona uma boa alternativa ao latão e outros tipos de ligas metálicas. Mesmo sendo mais frágil à corrosão em relação ao latão, o Zamac tem o substituído em diversas aplicações, não apenas pelo seu baixo custo, mas também pela facilidade de produzir peças com diversificação geométrica e de paredes finas, mantendo a resistência mecânica necessária para sua aplicação $[3,4]$. Apesar de todas as vantagens que esta liga proporciona, o maior problema das peças de Zamac injetadas sob pressão está na formação de porosidade em seu interior, originadas devido aos gases que são liberados durante o processo e, na

IInstituto de Ciências Criativas e Tecnológicas - ICCT, Universidade Feevale, Novo Hamburgo, RS, Brasil.

${ }^{2}$ Laboratório de Corrosão, Proteção e Reciclagem de Materiais - LACOR, Universidade Federal do Rio Grande do Sul - UFRGS, Porto Alegre, RS, Brasil.

*Autor correspondente: cto@feevale.br 
grande parte das situações, não migram por completo para as bolsas de gás que existem nos moldes, podendo assim comprometer a resistência mecânica das peças [5].

As ligas de Zamac geralmente apresentam estrutura cristalina formada por cristais hexagonais de zinco componentes da fase rica deste elemento, constituída também por uma matriz eutética desta mesma fase e de uma fase rica em alumínio de cristais cúbicos [6].

Ao longo dos anos estudos evidenciaram que após o resfriamento de ligas hipoeutéticas de Zamac pode ser evidenciado a formação de cristais primários dentríticos da fase rica de zinco. Indicada no diagrama de fase como fase $\eta$, tendo concentração de zinco de $98,86 \%$ e temperatura de $382{ }^{\circ} \mathrm{C}$. Esta fase apresenta estrutura cristalina hexagonal. Quando a temperatura cai abaixo desta faixa, a fase $\eta$ é envolvida por um eutético formado por esta mesma fase e uma segunda fase denominada fase $\beta$ que possui estrutura cúbica. A fase $\eta+\beta$ possui concentração de alumínio em torno de $22 \%$ e se mantem até a temperatura de $275^{\circ} \mathrm{C}$. Nesta temperatura, acontece uma reação eutetoide e transformando a fase $\eta+\beta$ em fase $\alpha+\eta[7,8]$.

A microestrutura do Zamac injetado sob pressão apresenta grãos mais refinados e melhor distribuídos em comparação com o Zamac fundido por gravidade. Isso mostra que o processo de produção tem influência na microestrutura do produto final $[5,9]$. As análises das microestruturas mostram de que quanto maior for a temperatura de fundição, mais tempo o Zamac vai demorar para se solidificar sem nenhuma ação externa, trazendo como consequência um maior tamanho de grão da peça solidificada. Outro fator importante é de que não houve presença de porosidade nas peças fundidas por gravidade neste estudo. Isto acontece, pois sem o resfriamento forçado como ocorre na injeção sob pressão, existe tempo suficiente para os gases migrarem para fora do material $[10,11]$. Portanto, este trabalho tem como objetivo propor um tratamento térmico em peças injetadas sob pressão com intuito de minimizar as porosidades geradas durante o processo.

\section{Materiais e métodos}

Amostras de Zamac Z5 injetado sob pressão foram fornecidas pela Metalúrgica Daniel LTDA. Estas peças foram produzidas em um único lote e injetadas em uma máquina injetora de Zamac com 125 toneladas de pressão de fechamento. Foi utilizado um molde de aço com 8 cavidades. A refrigeração foi realizada com água corrente para acelerar o processo, proporcionando um número maior de ciclos por hora. Todas as peças foram injetadas sob os mesmos parâmetros de temperatura, tempo e pressão. Elas foram, posteriormente, tratadas termicamente. Com a finalidade de verificar a influência do tratamento térmico nos defeitos dessas amostras, foi feita a caracterização de peças com e sem tratamento térmico, como mostrado na Tabela 1.

A preparação das amostras para análises de caracterização foi feita por meio de preparação metalográfica com lixamento e polimento. Para a análise da microestrutura das amostras foi feito ataque químico com Nital $5 \%$ por aproximadamente 10 segundos e, logo em seguida, as amostras foram lavadas com água e secas com ar frio. Após isso, as amostras foram metalizadas com um filme fino de ouro para garantir o contato elétrico necessário para realização da microscopia eletrônica de varredura em vista de topo. A análise da microestrutura foi realizada com o uso de um Microscópio Eletrônico de Varredura (MEV) modelo JEOL-JSM 6510CV com resolução de 129 eV. Para a análise do tamanho de grão e da porosidade da peça, foi utilizado o software free de tratamento de imagens chamado de Image J 1.50i.

\section{Resultados e discussões}

A Figura 1 apresenta a vista de topo das amostras Z-0, ZF-300 e ZF-250 analisadas ao MEV.

Nestas imagens estão mostradas magnificações de 150x (a esquerda) e 2000x (a direita). Observa-se que a amostra Z-0 apresenta pontos pretos distribuídos na superfície, o que indica a presença de poros, decorrentes do processo de injeção sob pressão [5], com tamanho aproximado de $10 \mu \mathrm{m}$ (magnificação 2000x). Aparentemente, estas porosidades encontram-se distribuídas de maneira uniforme. Isto pode acontecer devido a uma homogeneidade de processo de solidificação da peça. A incidência de porosidade é influenciada pela variação da taxa de resfriamento ao longo da amostra injetada [5]. Além disso, observa-se a microestrutura característica do Zamac, com uma fase primaria de solução sólida de zinco (fase $\eta$ ) e matriz eutética.

Com o tratamento térmico de $300^{\circ} \mathrm{C}$, por cinco minutos, e resfriamento dentro do forno (amostra ZF-300), também

Tabela 1. Nomenclatura das peças de Zamac 5 injetadas sob pressão de acordo com os tratamentos térmicos realizados

\begin{tabular}{cccc}
\hline AMOSTRA & CONDIÇÃO DE TRATAMENTO TÉRMICO & RESFRIAMENTO \\
\hline Z-0 & Sem tratamento & Sem tratamento \\
ZF-300 & Aquecido no forno até $300^{\circ}$ e mantido na temperatura por 5 minutos & Resfriado dentro do forno & Resfriado dentro do forno até $250^{\circ}$ e mantido na temperatura por 5 minutos \\
ZF-250 & Aquecido no forno até $200^{\circ}$ e mantido na temperatura por 5 minutos & Resfriado dentro do forno & Resfriado dentro do forno \\
ZF-200 & Aquecido no forno até $100^{\circ}$ e mantido na temperatura por 5 minutos & Apés a injeção a peça foi colocada em água & Resfriado em água \\
ZA-91 & Após a injeção a peça foi colocada em água em água &
\end{tabular}

Z-0 indica a amostra sem tratamento; ZF indica as amostras resfriadas dentro do forno; ZA indica as amostras resfriadas em água. 


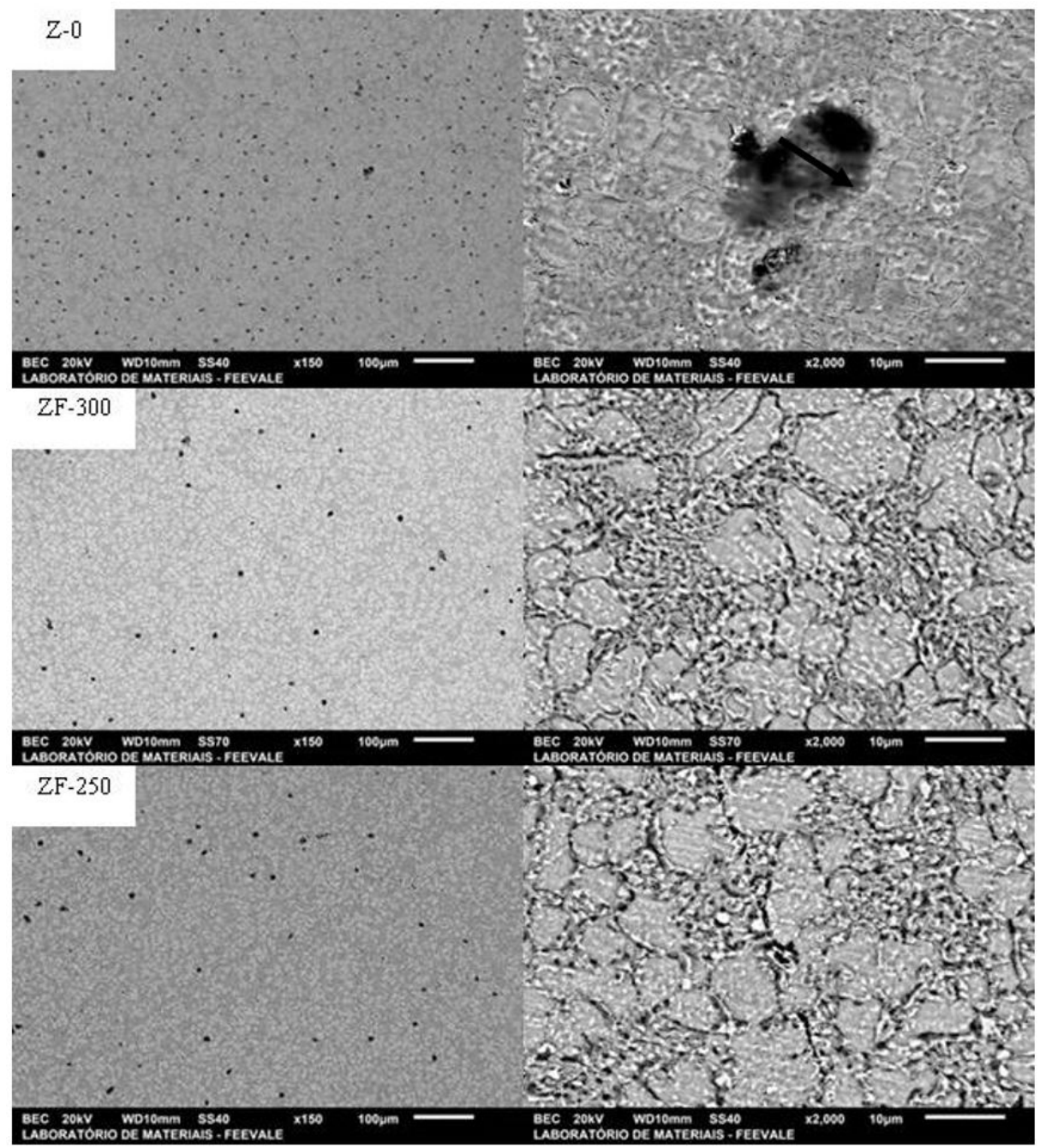

Figura 1. Micrografias das amostras Z-0, ZF-300 e ZF-250, resfriadas dentro do forno. Magnificações 150 e 2000x.

se observa a presença de poros na superfície. No entanto, em comparação a amostra Z-0, observa-se que a quantidade de porosidade é menor, mas com poros aparentemente maiores. Além disso, a quantidade de fase primária parece ter aumentado com o tratamento térmico. De acordo com o diagrama de fases $\mathrm{Zn}-\mathrm{Al}[12,13]$, na temperatura acima de $275^{\circ} \mathrm{C}$ ocorre a formação da fase $\eta$ em uma matriz eutética de $\eta+\beta$, ou seja, existe mudança de fase. Isto provavelmente deve ter ocasionado aumento de volume da rede cristalina, o que pode ter eliminado os poros menores.

A presença de elementos de liga, dentre eles o magnésio, podem aumentar a quantidade de solução sólida (fase primária), diminuir a quantidade de eutético e diminuir a quantidade da estrutura eutetoide lamelar. Para o tratamento térmico na temperatura de $250^{\circ} \mathrm{C}$ (amostra ZF-250) [14,15], observa-se um comportamento semelhante à amostra ZF-300. A Figura 2 apresenta as micrografias das amostras tratadas em ZF-200, ZF-150 e ZF-100.

No entanto, como pode ser observado na Figura 2, para a amostra tratada a $200^{\circ} \mathrm{C}(\mathrm{ZF}-200)$ e $150{ }^{\circ} \mathrm{C}(\mathrm{ZF}-150)$, pode ser evidenciada a ocorrência de porosidade semelhante à amostra sem tratamento. De acordo com a Figura 2, as amostras tratadas termicamente em temperatura abaixo do ponto eutetoide, deveriam apresentar o mesmo comportamento, uma vez que não ocorre mudança de fase. Porém o diagrama de fases $\mathrm{Zn}-\mathrm{Al}$, não leva em consideração a adição de elementos de liga, tais como cobre e magnésio. Sabe-se que a adição desses elementos pode baixar a temperatura do ponto eutetoide [16], o que explicaria o comportamento semelhante das amostras ZF-300 e ZF-250. A Figura 3 ilustra o diagrama de fases $\mathrm{Al}-\mathrm{Cu}-\mathrm{Zn}$.

De acordo com a Figura 3, existe a presença de duas fases no ponto eutetoide, abaixo daquela evidenciada no diagrama de fase $\mathrm{Zn}$-Al. Para a amostra tratada em $100^{\circ} \mathrm{C}$ (ZF-100), observa-se comportamento semelhante às amostras ZF-300 e ZF-250. Todavia isso não era esperado, uma vez que nessa temperatura não ocorre mudança de fase. A Figura 4 apresenta as micrografias das amostras ZA-90 e ZA-21.

No entanto, a amostra resfriada em água a $90^{\circ} \mathrm{C}$ após a injeção (ZA-90), são identificadas porosidades maiores que aquelas observadas na amostra Z-0, no entanto, aparentemente, 


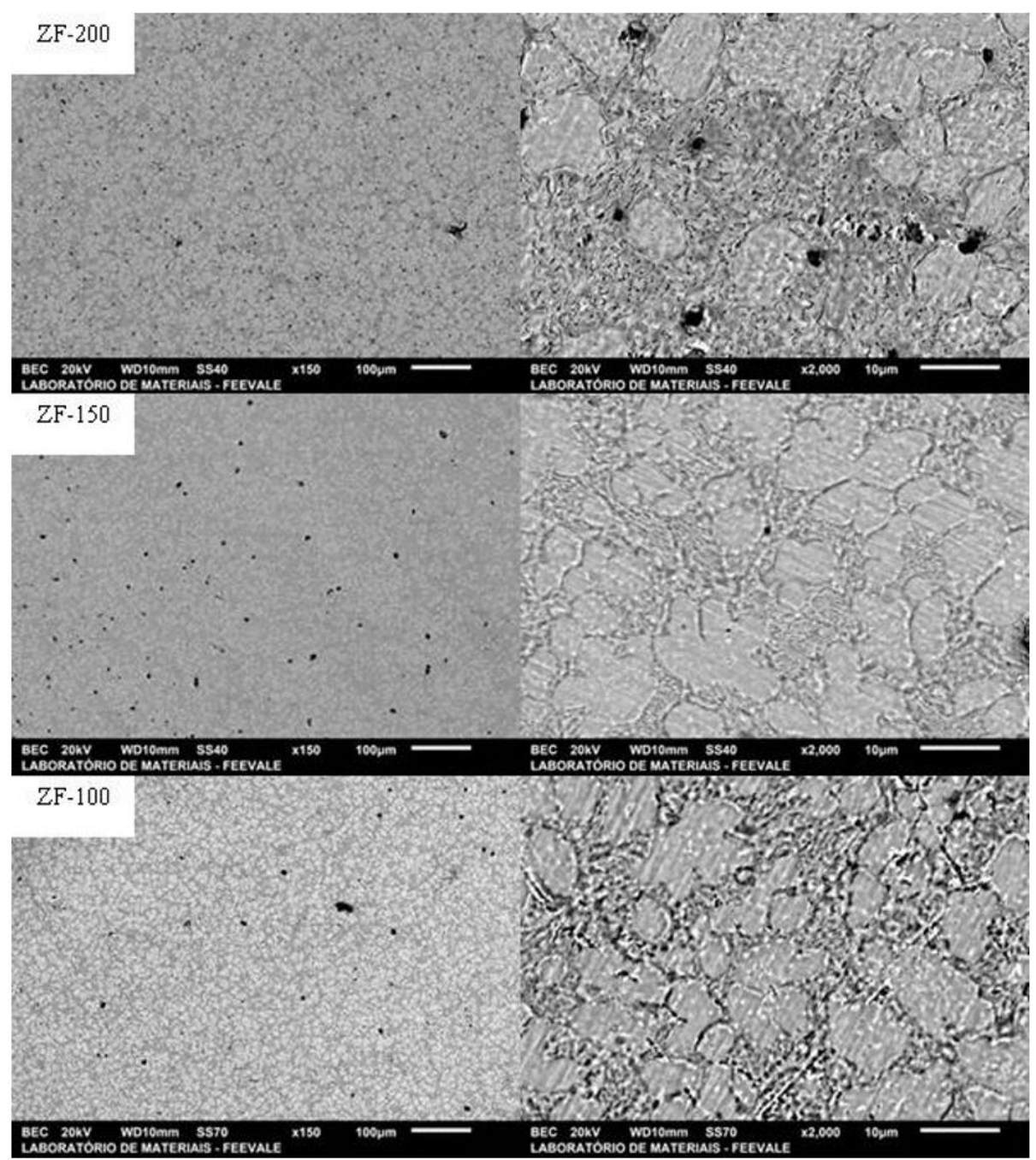

Figura 2. Micrografias das amostras ZF-200, ZF-150 e ZF-100 resfriadas dentro do forno. Magnificações 150 e 2000x.

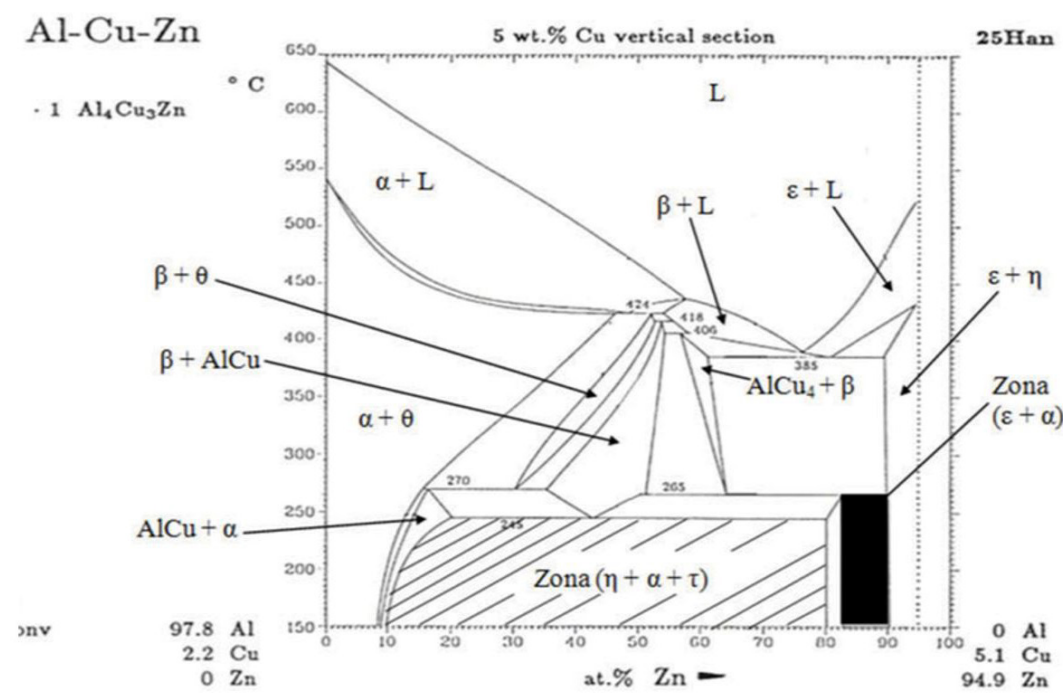

Figura 3. Diagrama de fase Al-Cu-Zn.

os poros não estão distribuídos de maneira homogênea. $\mathrm{O}$ tratamento térmico desta amostra foi diferente daquelas em que o resfriamento foi realizado dentro do forno. Esta amostra foi retirada do processo de injeção ainda quente e resfriada em água na temperatura inicial de $90^{\circ} \mathrm{C}$. Cabe salientar que não foi realizado o registro da temperatura da amostra após 


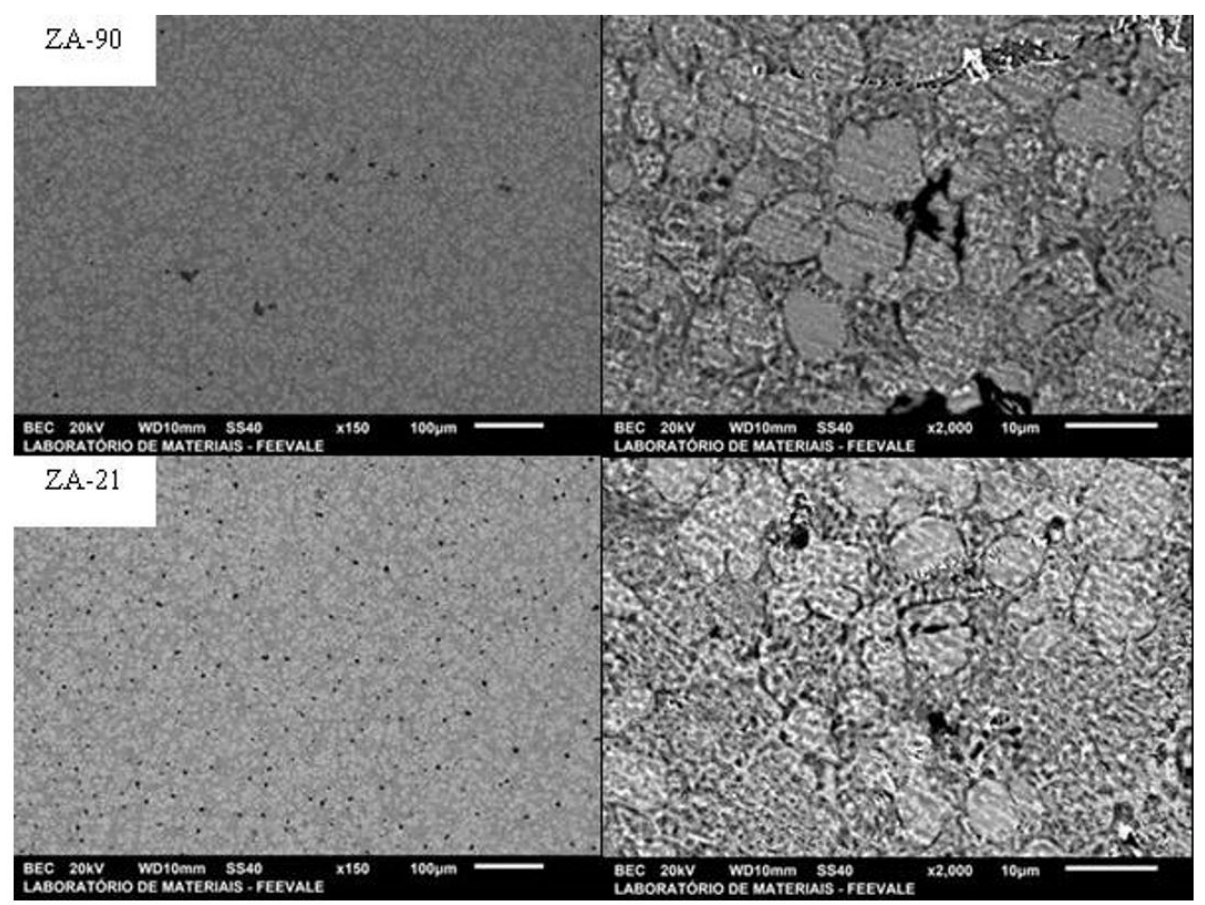

Figura 4. Micrografias das amostras ZA-90 e ZA-21 resfriadas em água, magnificações de 150 e 2000x.

Tabela 2. Quantificação dos defeitos das amostras de Zamac, bem como fase primária e eutética

\begin{tabular}{|c|c|c|c|c|c|c|}
\hline Amostra & Porosidade $/ \mu \mathrm{m}^{2}$ & $\begin{array}{l}\text { Área média do } \\
\text { grão }\left(\mu \mathrm{m}^{2}\right)\end{array}$ & Desvio padrão & $\begin{array}{c}\text { Área da solução } \\
\text { sólida }\left(\mu \mathrm{m}^{2}\right)\end{array}$ & $\begin{array}{l}\text { Área eutético } \\
\qquad\left(\mu \mathrm{m}^{2}\right)\end{array}$ & $\begin{array}{c}\% \text { de área } \\
\text { da solução } \\
\text { sólida / área total } \\
\end{array}$ \\
\hline Z-0 & $2,30 \mathrm{E}-04$ & 20,1 & 1,555 & 462,4 & 2354,5 & 16,42 \\
\hline ZF-300 & $2,00 \mathrm{E}-05$ & 26,95 & 1,879 & 1185,6 & 1631,3 & 42,09 \\
\hline $\mathrm{ZF}-250$ & $2,690 \mathrm{E}-05$ & 27,57 & 1,984 & 1185,6 & 1631,3 & 42,09 \\
\hline ZF-200 & $1,59 \mathrm{E}-04$ & 41,21 & 3,436 & 947,9 & 1869 & 33,65 \\
\hline ZF-150 & $1,07 \mathrm{E}-04$ & 27,38 & 2,079 & 1287 & 1529,9 & 45,69 \\
\hline ZF-100 & $2,10 \mathrm{E}-05$ & 27,79 & 2,020 & 1278,5 & 1538,4 & 45,39 \\
\hline ZA-90 & $2,00 \mathrm{E}-05$ & 26,07 & 1,828 & 1433,7 & 1383,2 & 50,9 \\
\hline ZA-21 & $1,20 \mathrm{E}-04$ & 29,73 & 2,359 & 773,1 & 2043,8 & 27,45 \\
\hline
\end{tabular}

ter sido desmoldada. Neste caso, como a amostra foi colocada quente, recém desmoldada, e resfriada, as porosidades se concentram em locais específicos, não ficando distribuídas homogeneamente. Por outro lado, deve-se levar em consideração o ataque químico da água ao zinco, que pode, também, ter influenciado no tamanho e distribuição dos poros.

Para a amostra resfriada em água a $21{ }^{\circ} \mathrm{C}$ (ZA-21), observa-se maior incidência de porosidade do que a amostra Z-0. Nela foi realizado um tratamento térmico em água a $21^{\circ} \mathrm{C}$. Sabe-se que durante o tratamento térmico ocorre mudança de fase sem difusão, o que deixa a estrutura cristalina tensionada e sujeita a trincas [17]. No caso da amostra em estudo, o tratamento térmico pode ter ocasionado sua contração, o que explicaria a maior incidência de porosidade observada.

Com uso do software Image $J$, foram calculados o número de porosidade $/ \mu \mathrm{m}^{2}$, bem como a área da fase primária contendo solução sólida e a área eutética para cada amostra através de análises morfológicas (obtidas ao MEV). Também foram obtidos os tamanhos de grão e, através dos dados, calculadas, as médias de área dos grãos de cada amostra, desvio padrão e a porcentagem de solução sólida em relação à área total de cada amostra, os quais estão mostrados na Tabela 2. Cabe salientar que a média da área do grão corresponde aos grãos da fase primária da solução sólida.

De acordo com os resultados da Tabela 2 verifica-se que a amostra Z-0, sem tratamento térmico, possui uma quantidade de porosidade $/ \mu \mathrm{m}^{2}$ da ordem de $10^{-4}$, com área média de grão de $20 \mu \mathrm{m} \pm 1,5$. Este valor foi bem superior ao encontrado por Führ, que foi de aproximadamente $4 \mu \mathrm{m}$ [5]. Neste caso, a peça estudada por Führ continha um volume menor do que a desse estudo, indicando uma taxa de resfriamento maior, e, portanto, grãos menores. Na amostra Z-0 o percentual de solução sólida em relação à área total é de 16,42\%. Este valor já era esperado, uma vez que a amostra foi injetada sob pressão e resfriada rapidamente.

As amostras ZF-300 e ZF-250 foram tratadas termicamente em temperaturas superiores ou muito próximas da temperatura onde ocorre mudança de fase. Estas duas amostras apresentaram redução na quantidade de porosidade $/ \mu \mathrm{m}^{2} \mathrm{em}$ relação à amostra Z-0, sendo obtido para estas amostras 
valores da ordem de $10^{-5}$. Além disso, apresentaram tamanho dos grãos pouco maiores, mas com um aumento da área de fase primária por solução sólida em comparação à área total, que foi de $42 \%$. Isto pode ser explicado devido à estrutura cristalina do zinco e do alumínio. O zinco possui uma estrutura cristalina hexagonal compacta $(\mathrm{HC})$, com seis átomos por célula unitária, enquanto o alumínio apresenta estrutura cristalina cúbica de face centrada (CFC) com 4 átomos por célula unitária. Isso faz com que o zinco tenha uma célula unitária maior do que o alumínio e ocupe um volume maior na rede cristalina [18], o que explicaria o aumento da área de solução sólida e diminuição das porosidades.

Por outro lado, o aquecimento da amostra até uma determinada temperatura e resfriamento dentro do forno até a temperatura ambiente, permite que ocorra um crescimento de grão mais uniforme, mediante a difusão de átomos $[18,19]$. Nesse caso, a energia necessária para que ocorra movimento difusivo de um mol de átomo de zinco é de $94000 \mathrm{~J} / \mathrm{Mol}$ que é menor do que a energia necessária para a difusão de um mol de alumínio, que é $144000 \mathrm{~J} / \mathrm{Mol}$ [19]. Durante o resfriamento, a partir da temperatura eutetoide, a decomposição dele, afeta somente a fase $\beta$ da estrutura lamelar do eutético, não afetando a fase $\eta[20]$.

Sendo a fase $\eta$ uma solução sólida rica em zinco e impurezas de alumínio, quando o tratamento térmico é realizado, a partir da temperatura eutetoide, os átomos de zinco da fase $\beta$ se movem preferencialmente do eutético para a solução sólida, por meio de difusão, diminuindo os espaços deixados pelas porosidades na solução sólida $[12,13]$. Acredita-se que este seja o motivo principal para a diminuicão da porosidade nas peças de Zamac tratadas termicamente [20].

A amostra ZF-200 não apresentou diminuição de porosidade em relação à amostra Z- 0 , como as duas amostras analisadas anteriormente. Porém, houve um aumento considerável na média de área do grão, com o maior desvio padrão entre as amostras analisada. Este comportamento pode ser evidenciado nas Figuras 1 e 2, em que se observam porosidades de tamanhos menores e maiores. Assim mesmo, o percentual de área de solução sólida nesta amostra ainda foi maior, $33,65 \%$, em comparação à amostra sem tratamento (Z-0), que foi de $16,42 \%$.

Para a amostra ZF-150, a diminuição da porosidade se apresentou em escala semelhante à da amostra ZF-200. As áreas dos grãos não tiveram tanta variação como na amostra anterior, porém, o aumento da área de solução sólida foi muito significativo, chegando a $45,69 \%$ da área total.

A amostra ZF-100 apresentou diminuição de porosidade e média de área de grão parecidas com as amostras ZF-300 e ZF-250, porém com desvio padrão levemente mais elevado que as amostras em comparação, o que indica variação ligeiramente maior no seu tamanho de grão. A porcentagem de área de solução sólida se assemelha muito com a da amostra ZF-150, sendo de 45,39\%. Os resultados descritos concordam com aqueles encontrados nas micrografias obtidas ao MEV (Figuras 1 e 2).
A amostra ZA-90, que, como já citado anteriormente, foi resfriada em água inicialmente em $90{ }^{\circ} \mathrm{C}$ logo após a injeção, apresentou uma diminuição na porosidade, por área, em relação à amostra $Z-0$, se assemelhando muito com as amostras ZF-300 e ZF-250. Também observou-se um comportamento muito semelhante na média da área do grão e no desvio padrão. De todas as amostras analisadas foi a que apresentou maior área de solução sólida chegando em 50,9\%. Esta amostra se assemelha a amostra de $100{ }^{\circ} \mathrm{C}$ resfriada dentro do forno. Apesar do resfriamento ter sido feito em água, ele foi lento, semelhante à amostra a $100^{\circ} \mathrm{C}$. No entanto, os poros aparecem em pontos isolados da amostra e não aleatoriamente, o que seria um indicativo de corrosão provocado pelo contato do Zamac com água quente [18].

A amostra ZA-21, quando comparada com a amostra Z-0, não apresentou melhorias significativas no número de porosidades por área, porém mostrou aumento de grão e maior variação no tamanho dos grãos. Já o aumento de área de solução sólida foi o menos significativo dentre todas as amostras analisadas.

Observa-se que, para todos os tipos de tratamentos térmicos realizados, houve aumento da área de solução sólida em relação à área total, indicando variação na microestrutura. Isto pode ser explicado, pois o Zamac injetado sob pressão passa por um processo de resfriamento muito rápido, o que pode tencionar o material, ocasionando o surgimento de grãos pequenos. Portanto qualquer tratamento térmico de aquecimento e resfriamento pode diminuir as tensões geradas durante a injeção sob pressão [21].

Alguns tratamentos mostraram diminuição da quantidade de poros e aumento do tamanho de grãos, o que foi atribuído à difusão de zinco com aumento de volume da célula unitária. Observou-se que não existe variação nas dimensões das amostras. Neste caso, pode-se supor que o aumento do volume ocasionado pela difusão dos átomos de zinco para formação de célula unitária hexagonal compacta não interferiu nas dimensões das peças [22].

\section{Conclusões}

O trabalho apresentado tratou do estudo da melhor condição de tratamento térmico para minimizar os defeitos de porosidade do Zamac. Para tanto, as seguintes conclusões são apresentadas:

As amostras tratadas termicamente nas temperaturas acima da eutetoide, ZF-300 e ZF-250, apresentaram menor porosidade em comparação à amostra sem tratamento, o que foi atribuído à mudança de fase durante o tratamento térmico.

O aumento do tamanho do grão da fase primária de solução sólida, proveniente do tratamento térmico dentro do forno, foi atribuído à difusão do zinco preferencialmente à do alumínio. Além disso, as amostras tratadas a $100^{\circ} \mathrm{C}$, ZF-100, apresentaram baixa porosidade em comparação à amostra sem tratamento, Z-0. 
As amostras tratadas em água não apresentaram resultado satisfatório, com relação à diminuição da porosidade, em comparação à amostra Z-0. Contudo, observou-se que, todas as amostras apresentaram aumento da área de solução sólida em relação à área total, para todos os tratamentos térmicos apresentados.

Portanto, foi verificado que a melhor condição de tratamento térmico para minimizar os defeitos de porosidade são aqueles com aquecimento da peça acima da temperatura eutetoide, com tempo de permanência suficiente para que toda a peça atinja a temperatura desejada, seguida de resfriamento dentro do forno.

\section{Agradecimentos}

Os autores agradecem à Metalúrgica Daniel LTDA, ao Laboratório de Estudos Avançados em Materiais da Universidade Feevale, à CAPES, CNPq, FAPERGS E INCTINES (Instituto Nacional de Engenharia de Superfície).

\section{Referências}

1 Wu Z, Sandlöbes S, Wu L, Hu W, Gottstein G, Korte-Kerzel S. Mechanical behaviour of Zn-Al-Cu-Mg alloys: Deformation mechanisms of as-cast microstructures. Materials Science and Engineering: A. 2016;651:675-687.

2 Wang F, Xiong B, Zhang Y, Liu H, Li Z, Li X, et al. Effect of Cu addition on microstructure and corrosion behavior of spray-deposited Zn-30Al alloy. Materials Science and Engineering: A. 2012;532:100-105.

3 Shin S, Lim K, Park I. Characteristics and microstructure of newly designed AleZn-based alloys for the die-casting process. Journal of Alloys and Compounds. 2016;671:517-526.

4 Marder AR. The metallurgy of zinc-coated steel. Progress in Materials Science. 2000;45(3):191-271.

5 Führ LT. Influência dos defeitos de solidificação na resistência à corrosão do Zamac. Novo Hamburgo: Universidade Feevale; 2012.

6 Marcolin P, Longhi M, Zini LP, Proença B, Malfatti CF, Battisti LC, et al. Influence of the pH and stirring speed of the electrodeposition bath in the performance of zinc and zinc-nanocomposite coatings. Materials Science Forum. 2017;899:283-288.

7 Ganivet M. Metalurgia das ligas de zinco: fundição. Belo. Horizonte: Serviço Nacional de Aprendizagem Industrial; 1987. (vol. 11).

8 Mojaver R, Shahverdi HR. Relationship between cooling rate, microstructure features and wear behavior in end-chill cast $\mathrm{Zn}-27 \% \mathrm{Al}$ alloys containing more than 2\% Cu. Wear. 2011;271(11-12):2899-2908.

9 Domínguez-Ríos C, Moreno MV, Torres-Sánchez R, Antúnez W, Aguilar-Elguézabal A, González-Hernández J. Effect of tartrate salt concentration on the morphological characteristics and composition of $\mathrm{Cu}-\mathrm{Zn}$ electroless plating on zamak 5 zinc alloy. Surface and Coatings Technology. 2008;202(19):4848-4854.

10 Pinto H, Silva FJG. Optimisation of die casting process in Zamak alloys. Procedia Manufacturing. 2017;11:517-525.

11 Martinez Page MA, Weidenfeller B, Hartmann S. Influence of temperature and aging on the thermal diffusivity, thermal conductivity and heat capacity of a zinc die casting alloy. Journal of Alloys and Compounds. 2019;786(25):1060-1067.

12 American Society for Metals. Metals handbook. Metals Park: ASM. Metallography and microstructures. (vol. 9).

13 American Society for Metals. Metals handbook. Metals Park: ASM. Properties and selection: nonferrous alloys and special: purpose materials. (vol. 2).

14 Costa EM, Costa CE, Vecchia FD, Rick C, Scherer M, Santos CA, et al. Study of the influence of copper and magnesium additions on the microstructure formation of $\mathrm{Zn}-\mathrm{Al}$ hypoeutectic alloys. Journal of Alloys and Compounds. 2009;488(1):89-99.

15 Rick CF. Estudo da liga à base de Zn-Al-Cu-Mg aplicada na fabricação de jóias folhadas. Porto Alegre: PUCRS; 2006.

16 Elvins J, Spittle JA, Worsley DA. Microstructural changes in zinc aluminium alloy galvanising as a function of processing parameters and their influence on corrosion. Corrosion Science. 2005;47(11):2740-2759.

17 Mapelli RF, Malfatti CF, Oliveira CT. Zinco: características e aplicações como elemento no desenvolvimento de tecnologia. Tecnologia e Tendências. 2014;9(1):1-12.

18 Marcolin P, Longhi M, Zini LP, Kunst SR, Zattera AJ, Fuhr LT, et al. Effects of the casting temperature in the leakage of Zamak 5. Materials Science Forum. 2017;899:458-462.

19 Callister WD. Ciência e engenharia de mateirias: uma introdução. 7. ed. Rio de Janeiro: LTC; 2008. 
20 Schürz S, Luckeneder GH, Fleischanderl M, Mack P, Gsaller H, Kneissl AC, et al. Chemistry of corrosion products on Zn- Al-Mg alloy coated steel. Corrosion Science. 2010;52(10):3271-3279.

21 Kim S-J, Kim K-S, Kim S-S, Kang C-Y, Suganuma K. Characteristics of Zn-Al-Cu alloys for high temperature solder application. Materials Transactions. 2008;49(7):1531-1536.

22 Führ LT, Ludwig GA, Martins MR, Vecchia FD, Rieder EC, Malfatti C, et al. Effects of mould temperature in squeeze casting of Zamak 5. Materials Science Forum. 2014;775-776:729-732.

Recebido em: 8 Abr. 2019

Aceito em: 23 Jun. 2020 